\title{
Position Estimation in Induction Machines Utilizing Rotor Bar Slot Harmonics and Carrier-Frequency Signal Injection
}

\author{
Michael W. Degner, Associate Member, IEEE, and Robert D. Lorenz, Fellow, IEEE
}

\begin{abstract}
This paper presents a simple and robust way of utilizing harmonic saliencies created by rotor and stator slotting, present in some induction machine designs, for the estimation of rotor position. The injection of a carrier-signal voltage, in addition to the fundamental excitation, produces a carrier-signal current that contains the desired spatial information. A closed-loop tracking observer is then used to extract this spatial information for the estimation of the rotor position. Due to its reliance on a spatial saliency and carrier-frequency signal injection, the technique is very robust over a wide speed range, including low and zero speed.
\end{abstract}

Index Terms-Carrier injection methods, saliency sensing, saliency tracking, sensorless control.

\section{INTRODUCTION}

$\mathbf{T}$ HE cost and reliability advantages of eliminating mechanical sensors and cabling for the measurement of position, velocity, and flux has led to active research into what is commonly termed "sensorless" or "self-sensing" control of ac machines. The goal of this research is to estimate the rotor position or flux angle using the power leads of the machine, without separate position, velocity, or flux transducers. Many of these methods depend on the fundamental excitation of the machine and speed dependent phenomenon (back EMF), causing them to ultimately fail at low and zero speed [1]-[4].

Several researchers [5]-[20] have developed methods to estimate rotor position or flux angle that rely on a spatial saliency being present in the machine. These methods can be divided into two major groups: 1) those that use the fundamental excitation to estimate the rotor position or flux angle [5]-[10] and 2) those that use a separate excitation signal from the fundamental excitation to estimate the rotor position or flux angle [11]-[20]. The reliance on the fundamental excitation ultimately causes the methods in group one to fail at low and zero speed due to

Paper IPCSD 99-90, presented at the 1997 IEEE/IEEJ Joint IAS Power Conversion Conference-Nagaoka, Nagaoka, Japan, August 3-6, and approved for publication in the IEEE TRANSACTIONS ON INDUSTRY APPLICATIONS by the Industrial Drives Committee of the IEEE Industry Applications Society. Manuscript submitted for review May 1, 1998 and released for publication December 20, 1999. This work was supported by Ford Motor Company and the Wisconsin Electric Machines and Power Electronics Consortium (WEMPEC), University of Wisconsin, Madison.

M. W. Degner is with Ford Research Laboratory, Ford Motor Company, Dearborn, MI 48121-2053 USA (e-mail: mdegner@ ford.com).

R. D. Lorenz is with the Department of Mechanical Engineering and the Department of Electrical and Computer Engineering, University of Wisconsin, Madison, WI 53706 USA (e-mail: lorenz@engr.wisc.edu).

Publisher Item Identifier S 0093-9994(00)03171-6. low signal levels, signal-to-noise ratio, and lack of spectral separation between the signal with the spatial information and the fundamental excitation. The methods in group two do not suffer from these same problems at low and zero speed since they do not rely on the fundamental excitation for their estimation. Instead they rely on a separate, known test or carrier signal to extract the spatial information.

This paper extends the techniques presented in [14]-[20] to the estimation of rotor position in induction machines that have a parasitic saliency present due to number of rotor and stator slots used in the machine design. The paper first develops how the rotor and stator slots can interact to produce a harmonic saliency and then systematically looks at the differences in the estimation technique that results from using a harmonic saliency for the estimation of rotor position. The techniques developed in this paper are then applied to an induction motor to estimate its rotor angle using the saliency created by the interaction of the rotor and stator slots.

\section{SAliencies Produced by Rotor and Stator Slotting}

The presence of rotor and stator slots in induction machines creates variations in the air-gap permanence that can interact with the stator winding distribution to produce inductance variations [19]. A simple graphical way of seeing how the rotor and stator slotting can interact to produce these permanence variations is shown in Fig. 1. In this figure, the stator and rotor slotting are modeled by alternating segments colored white and black. The white segments represent areas of high permanence, where the flux would prefer to flow, and the black areas represent areas of low permanence, where the flux would not easily flow.

From Fig. 1, it can be seen that, in addition to creating permanence variations that repeat with a period equal to the slot pitch of the stator and rotor, Fig. 1(a) and (b), respectively, the rotor and stator slotting interact to produce a permanence variation with a lower spatial frequency, Fig. 1(c), where the rotor and stator permanence variations have been overlayed. The period of this low spatial frequency permanence variation is equal to $2 \pi$ divided by the difference between the number of rotor and stator slots.

The permanence variation created by the interaction of the rotor and stator slotting has some very interesting behaviors. If the representation of the rotor slotting shown in Fig. 1(b) is rotated through an angle exactly equal to the rotor slot pitch, the rotor slot permanence variation will be identical to permanence 

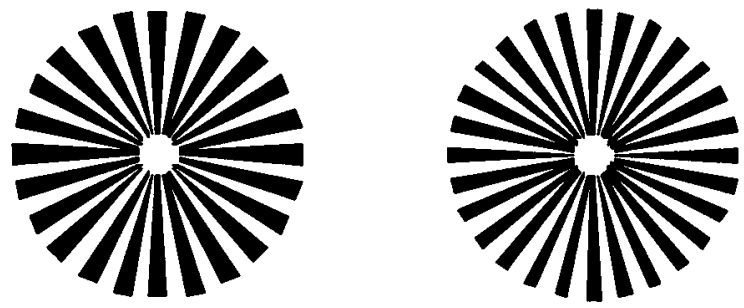

(a)

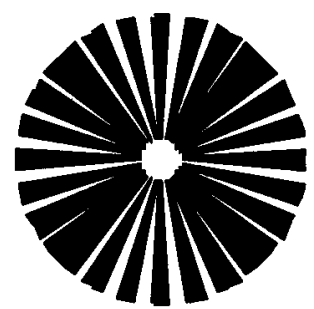

(b)

Fig. 1. Graphical representation of the air-gap permanence variation created by rotor and stator slotting (28 rotor slots and 24 stator slots). (a) Stator slotting ( $S=24)$. (b) Rotor slotting $(R=28)$. (c) Overlay of rotor and stator slotting.

variation before the rotor was rotated. This means that the interaction of the rotor and stator slot permeances will also be identical to that of the original rotor position, Fig. 1(c). From this behavior it can be deduced that the permanence variation caused by the interaction of the rotor and stator slotting must rotate at a multiple of the actual rotor speed. The relationship between the angular velocity of the airgap permanence variation and the rotor speed is given by (1)

$$
\omega_{a g p}=\frac{R}{(R-S)} \omega_{r m}
$$

where

$\omega_{\text {agp }}$ angular velocity of the air-gap permanence variation;

$\omega_{\mathrm{rm}}$ mechanical speed of the rotor;

$R \quad$ number of rotor slots;

$S$ number of stator slots.

A second interesting behavior of the permanence variation created by the interaction between the rotor and stator slotting can be seen from (1). When the number of rotor slots is greater than the number of stator slots the air-gap permanence variation will rotate in the same direction as the rotor (i.e., the angular velocity of the air-gap permanence variation has the same sign as the rotor speed). When the number of rotor slots is less than the number of stator slots, the air-gap permanence variation will rotate in the opposite direction as the rotor (i.e., the angular velocity of the air-gap permanence variation has the opposite sign as the rotor speed). The permanence variation created by the rotor and stator slotting can interact with the stator windings to create an inductance variation if the periods of its fundamental or any harmonics are equal to the period of the fundamental, or harmonics, of the stator winding distribution. The relationship between the number of rotor slots, stator slots, and poles that must exist for this to occur can be calculated using winding functions and Fourier series approximations to the permanence variations caused by the rotor and stator slotting and is given in (2), [19]. Note that the relationship shown in (2) is the most important of several relationships that result in an inductance variation. The others are not discussed here since they will only result in a significant inductance variation under special circumstances

$$
u P=|n R-m S|
$$

where

$P \quad$ number of poles;

$u \quad$ harmonic number of the stator winding distribution;

$n$ harmonic number of the rotor slotting permanence variation;

$m$ harmonic number of the stator slotting permanence variation.

Of particular interest are the cases where the fundamental of the permanence variation created by the rotor and stator slotting interact with the fundamental of the stator winding distribution [u, $n$, and $m$ are all equal to 1 in (2)] since this will tend to create the largest rotor position inductance variation.

It should be noted that, when excited by the fundamental excitation, the saliency discussed in this section produces the signal that is used by the techniques presented in [5]-[10].

\section{SAlient AC MAChine High-FreQUenCy Model}

The dynamic equations that model an induction machine in the stationary reference frame are given in (3)-(6)

$$
\begin{aligned}
& v_{q d s}^{s}=r_{s} i_{q d s}^{s}+p \lambda_{q d s}^{s} \text { stator voltage equation } \\
& 0=r_{r} i_{q d r}^{s}+\left(p-j \omega_{r}\right) \lambda_{q d r}^{s} \text { rotor voltage equation }
\end{aligned}
$$

where

$$
\begin{aligned}
& \lambda_{q d s}^{s}=L_{s} i_{q d s}^{s}+L_{m} i_{q d r}^{s} \text { stator flux linkage } \\
& \lambda_{q d r}^{s}=L_{m} i_{q d s}^{s}+L_{r} i_{q d r}^{s} \text { rotor flux linkage. }
\end{aligned}
$$

At high frequencies, the stator and rotor resistances can be neglected, resulting in the simplified equations shown in

$$
\begin{aligned}
v_{q d s}^{s} & \cong p \lambda_{q d s}^{s} \cong p\left(L_{s} i_{q d s}^{s}+L_{m} i_{q d r}^{s}\right) \\
0 & \cong\left(p-j \omega_{r}\right) \lambda_{q d r}^{s} \cong\left(p-j \omega_{r}\right)\left(L_{m} i_{q d s}^{s}+L_{r} i_{q d r}^{s}\right) .
\end{aligned}
$$

For fixed-frequency excitation at a carrier frequency $\omega_{c}$, the $p$ operator can be replaced with $j \omega_{c}$ and the rotor equation (8) can be used to develop an equation between the rotor and stator currents as shown in

$$
\begin{aligned}
& 0 \cong j\left(\omega_{c}-\omega_{r}\right) \lambda_{q d r}^{s} \cong j\left(\omega_{c}-\omega_{r}\right)\left(L_{m} i_{q d s}^{s}+L_{r} i_{q d r}^{s}\right) \\
& i_{q d r}^{s} \cong-\left(\frac{L_{m}}{L_{r}}\right) i_{q d s}^{s} .
\end{aligned}
$$

Substituting this result back into the stator equation (7) results in the simplified high frequency machine model shown in

$$
v_{q d s} \cong j \omega_{c} L_{\sigma s} i_{q d s}
$$


where the stator transient inductance $L_{\sigma s}$ is equal to

$$
\left(L_{s}-\frac{L_{m}^{2}}{L_{r}}\right) \text {. }
$$

When a rotor-position-dependent saliency is present in the machine, the stator transient inductance is no longer constant and instead becomes a function of the rotor position. In the stationary reference frame, the stator transient inductance matrix can be represented as shown in

$L_{\sigma s}=\left[\begin{array}{cc}\Sigma L_{\sigma s}+\Delta L_{\sigma s} \cos \left(h \theta_{r}\right) & -\Delta L_{\sigma s} \sin \left(h \theta_{r}\right) \\ -\Delta L_{\sigma s} \sin \left(h \theta_{r}\right) & \Sigma L_{\sigma s}-\Delta L_{\sigma s} \cos \left(h \theta_{r}\right)\end{array}\right]$

where

$\sigma L_{\sigma s}$ average stator transient inductance;

$\Delta L_{\sigma s}$ differential stator transient inductance caused by the saliency;

$h$ harmonic number of the saliency (equal to twice the ratio between the angular speed that the saliency rotates at and the speed of the rotor, and can be positive, negative, or zero);

$\theta_{r} \quad$ rotor position in electrical degrees.

\section{CARRIER SignAL InJECTION}

The estimation of rotor position at low and zero speed requires a persistent excitation in the machine. The switching harmonics created by the inverter are one option for this persistent excitation. Although these harmonics do satisfy the persistent excitation requirement, there are several limitations associated with their use for saliency-based position estimation. First, depending on the size and power rating of the drive, the switching harmonics may be at frequencies that do not properly excite the saliency, making the extraction of the spatial information much more difficult, if not impossible. Second, the switching harmonics are not generally in a form that lends itself to simple signal processing. As will be shown in the following discussion, excitation that is in the form of a constant-magnitude constant-frequency rotating vector leads to very simple and robust signal processing techniques for the extraction of the spatial information. Finally, the lack of spectral separation between the various components of the switching harmonics makes their separation more difficult and may degrade the quality of the estimate.

Another option for providing the persistent excitation is through the injection of a carrier signal in addition to the fundamental excitation [14]-[20]. One of the simplest forms of carrier signal injection is the injection of a balanced three-phase voltage [14]-[16], [18]-[20]. This type of carrier-signal injection produces a constant-amplitude voltage vector that rotates at the carrier frequency (13). Note that only voltage carrier-signal voltage excitation will be discussed in this paper, but the excitation could also be provided by injecting a balanced three-phase current

$$
v_{q d s_{-} c}^{s}=\left[\begin{array}{c}
v_{q s_{-}}^{s} \\
v_{d s_{-} c}^{s}
\end{array}\right]=V_{s c}\left[\begin{array}{c}
\cos \left(\omega_{c} t\right) \\
-\sin \left(\omega_{c} t\right)
\end{array}\right]=V_{s c} e^{j \omega c t} .
$$

The carrier-signal excitation can be injected into the machine on top of the fundamental excitation by adding it to the voltage

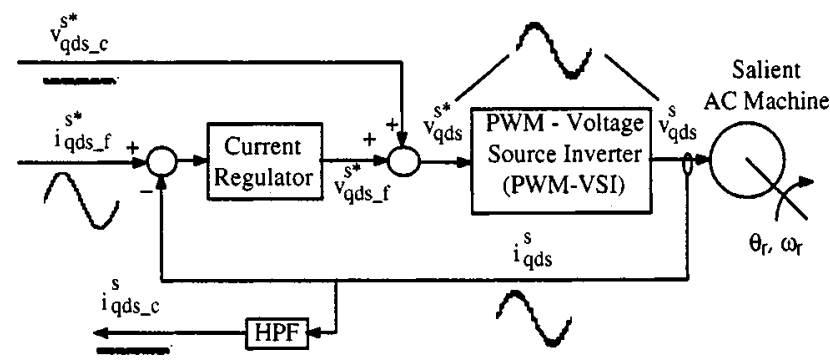

Fig. 2. Injection of carrier signal excitation using a PWM-VSI.

command generated by the current regulator and using a pulsewidth-modulated voltage-source inverter (PWM-VSI), as shown in Fig. 2.

When a salient machine, with a stator transient inductance modeled by (12), is excited with the carrier-signal voltage excitation (13), carrier signal currents will be induced equal to

$$
\begin{aligned}
i_{q d s_{-} c}^{s} & =\left[\begin{array}{l}
i_{q s_{-} c}^{s} \\
i_{d s_{-} c}^{s}
\end{array}\right]=I_{c p}\left[\begin{array}{l}
\sin \left(\omega_{c} t\right) \\
\cos \left(\omega_{c} t\right)
\end{array}\right]-I_{c n}\left[\begin{array}{c}
\sin \left(h \theta_{r}-\omega_{c} t\right) \\
\cos \left(h \theta_{r}-\omega_{c} t\right)
\end{array}\right] \\
& =-j I_{c p} e^{j \omega c t}+j I_{c n} e^{j(h \theta r-\omega c t)}
\end{aligned}
$$

where

$$
\begin{aligned}
I_{c p} & =\frac{V_{s c}}{\omega_{c}\left(\Sigma L_{\sigma s}^{2}-\Delta L_{\sigma s}^{2}\right)} \Sigma L_{\sigma s} \\
I_{c n} & =\frac{V_{s c}}{\omega_{c}\left(\Sigma L_{\sigma s}^{2}-\Delta L_{\sigma s}^{2}\right)} \Delta L_{\sigma s} .
\end{aligned}
$$

The carrier signal current can be seen to consist of the following two components:

1) a positive-sequence component relative to the carrier-signal voltage that contains no spatial information (this positive-sequence component is proportional to the average stator transient inductance);

2) a negative-sequence component relative to the carrier-signal voltage that contains spatial information in its phase (this negative-sequence component is proportional to the differential stator transient inductance).

The selection of the carrier-signal frequency is dependent upon the magnitude of the saliency, the switching frequency of the inverter, and the range of fundamental frequencies where the carrier-signal-based estimation will be used. In general, the carrier-signal frequency should be spectrally separated from both the fundamental frequency and the switching frequency to aid in its isolation. The allowable magnitude of the carrier-signal voltage and current also constrains the carrier-signal frequency. For a given level of carrier-signal voltage, higher carrier-signal frequencies will, in general, produce less carrier-signal current. Finally, the behavior of the machine at high frequencies places a final constraint on the carrier-signal frequency. As the frequency increases, the carrier signal produces less flux that will cross the air gap to the rotor due to skin effects. This results in less spatial information being present in the carrier signal as the frequency increases. As a general guideline, the optimal carrier signal frequency is usually in the frequency range between several hundred of hertz but less than several kilohertz $(\sim 200 \mathrm{~Hz}-3 \mathrm{kHz})$. It must be emphasized that this is just a general guideline and 


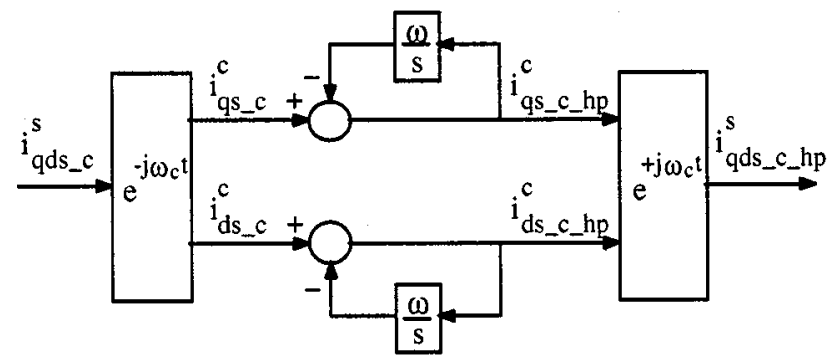

Fig. 3. Positive-sequence carrier-signal synchronous reference frame high-pass filter.

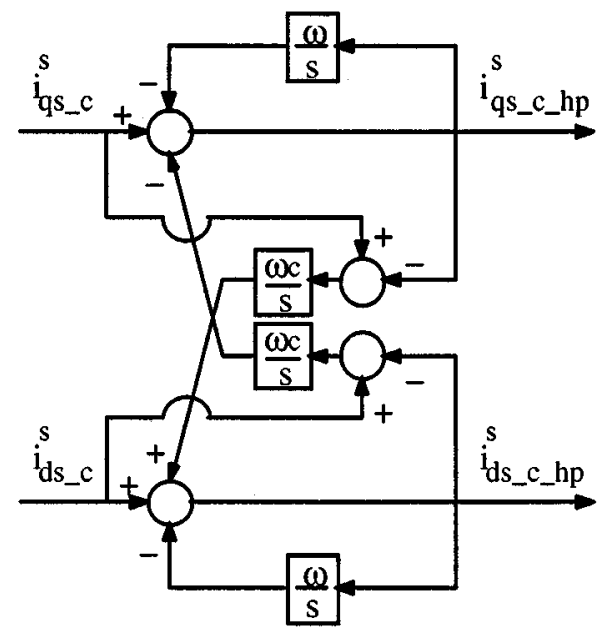

Fig. 4. Positive-sequence carrier-signal synchronous reference frame high-pass filter implemented in the stationary reference frame.

the actual optimal carrier signal frequency is very machine and application dependent.

Because there are two distinct components to the carrier signal current, and only one of them contains any spatial information, it is desirable to filter off the component which contains no spatial information.

\section{SYNCHRONOUS REFERENCE FRAME FILTERING}

Since the two components of the carrier-signal current rotate in opposite directions, it is relatively easy to filter off the component with no spatial information. Transforming the carrier-signal current to a reference frame synchronous with the positive-sequence component causes the positive-sequence component to become a dc quantity. A simple high-pass filter can then be used to totally filter off the positive-sequence component. The implementation of this positive-sequence carrier-signal synchronous reference frame high-pass filter is shown in Fig. 3. Because the signal that is being filtered off is a dc quantity, the order and the bandwidth of the filter do not have to be very high to achieve adequate filtering.

It is also possible to implement the synchronous reference frame filtering in a stationary reference frame as shown in Fig. 4. In the stationary reference frame, the filter is a linear system if the carrier frequency is constant.

Additional synchronous reference frame filters can also be used to filter off the fundamental component of the stator

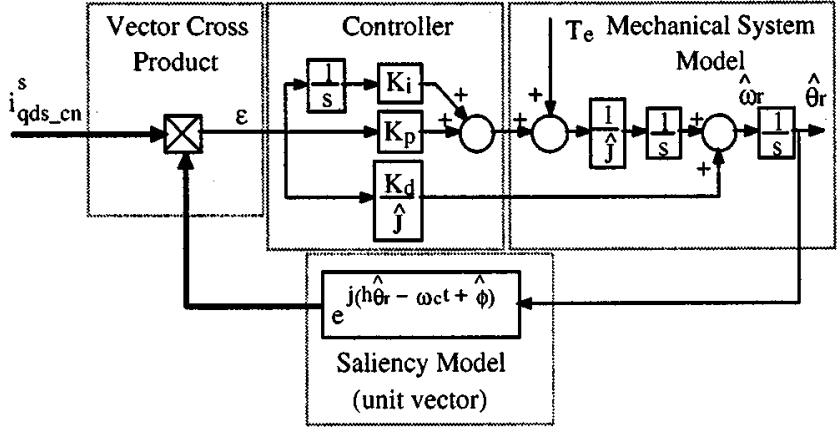

Fig. 5. Tracking observer for the estimation of rotor position in a machine with a harmonic saliency.

current. Filtering the fundamental component in this way is a little more complex than just using a stationary reference frame high-pass filter for the purpose. This increased complexity has to be traded off with the improved filtering provided by the synchronous reference frame high-pass filter.

\section{ROTOR POSITION ESTIMATION}

With the fundamental excitation and the positive-sequence component of the carrier-signal current filtered off, it is possible to extract the spatial information contained in the phase of the negative-sequence component of the carrier-signal current using the tracking observer shown in Fig. 5.

The error signal, which forces the estimated rotor position to track the actual rotor position, is formed by taking the vector cross product between an estimate of the negative-sequence carrier-signal current vector, formed by a saliency model, and the measured negative-sequence carrier-signal current vector

$$
\varepsilon=\hat{i}_{q d s_{-} c}^{s} \times i_{q d s_{-} c}^{s}=I_{c n} \sin \left(h\left(\theta_{r}-\hat{\theta}_{r}\right)\right) .
$$

Since the spatial information is contained in phase of the negative-sequence carrier-signal current vector, it is not important for the estimated vector to accurately model the magnitude of the measured vector, only its phase. The reliance on only the phase is important since it makes the estimation independent of any machine parameters, which may vary. The simplest form for an estimated negative-sequence carrier-signal current vector is a unit vector as shown in Fig. 5.

The gains $\left(K_{i}, K_{p}\right.$, and $\left.K_{d}\right)$ used in the tracking observer are determined by the desired bandwidth of the rotor position estimate. One important limitation on the achievable bandwidth is the amount of spectral separation between the negative-sequence carrier-signal current and the other components of the stator current, including noise. If the bandwidth of the tracking observer is tuned too high, these other components will produce error in the position estimate and, at very high bandwidths, may cause instability.

The use of a harmonic saliency for the estimation of rotor position affects the tracking observer in several ways. First, the harmonic number of the saliency scales the estimated position error. This scaling of the estimated position error is shown in (16) with the assumption of a small estimated position error

$$
\varepsilon \approx I_{c n} h\left(\theta_{r}-\hat{\theta}_{r}\right) .
$$


TABLE I

MACHINE PARAMETERS

\begin{tabular}{ll}
\hline \multicolumn{1}{c}{ Parameter } & \multicolumn{1}{r}{ Value } \\
\hline$r_{s}$ & $0.0135 \Omega$ \\
$r_{r}$ & $0.0140 \Omega$ \\
$L_{l s}$ & $0.065 \mathrm{mH}$ \\
$L_{l r}$ & $0.078 \mathrm{mH}$ \\
$L_{m}$ & $0.530 \mathrm{mH}$ \\
$\Sigma L_{\sigma s}$ & $0.133 \mathrm{mH}$ \\
$\Delta L_{\sigma s}$ & $0.016 \mathrm{mH}$ \\
rated speed & $450 \mathrm{rpm}$ \\
rated torque & $4.82 \mathrm{~N} \mathrm{~m}$ \\
rated current & $120 \mathrm{~A}$ \\
poles & 4 \\
stator slots & 24 \\
rotor slots & 28 \\
dc bus voltage & $12 \mathrm{~V}$ \\
\hline
\end{tabular}

This scaling of the estimated position error must be accounted for in the calculation of the tracking observer gain.

A second way a harmonic saliency affects the estimation is by increasing the number of stable operating points that the observer may operate about. The number of stable operating points can be calculated from (15) by finding how many estimated rotor position values, for a given actual rotor position, result in the estimated position error being equal to zero while the partial derivative of the error signal with respect to the estimated rotor position is negative

$$
\begin{gathered}
\varepsilon=I_{c n} \sin \left(h\left(\theta_{r}-\hat{\theta}_{r}\right)\right)=0 \\
\frac{\partial \varepsilon}{\partial \hat{\theta}_{r}}=-h I_{c n} \cos \left(h\left(\theta_{r}-\hat{\theta}_{r}\right)\right)<0 .
\end{gathered}
$$

For a saliency that rotates at the same speed as the rotor, $h=2$, there are two stable operating points per electric revolution or a value equal to the number of poles, $P$, per mechanical revolution. For a harmonic saliency, $|h|>2$, the number of stable operating points is equal to the number of pole pairs times the absolute value of the harmonic number per mechanical revolution. The general relationship for determining the number of stable operating points, valid for any harmonic number, is given in

$$
\text { number of stable operating points }=|h| \frac{P}{2} \text {. }
$$

This increase in the number of stable operating points, as $h$ increases, results in an increase in the effective resolution of the rotor position estimate.

\section{EXPERIMENTAL RESULTS USING ROTOR BAR SLOT HARMONICS}

The saliency model and position estimation technique described in the previous sections was implemented using a Texas Instruments TMS320C31 digital signal processor (DSP) system on an induction machine with the parameters shown in Table I. This induction machine and DSP system was supplied by the Ford Motor Company and was custom built for an automotive application (note: $14-\mathrm{V}$ dc bus). The switching frequency of the inverter and the sample rate of the DSP were synchronized at 10 $\mathrm{kHz}$. All control and estimation calculations were performed at this $10-\mathrm{kHz}$ sample rate.

Although the test induction machine was custom built for its application, it was not specifically designed to produce the saliency needed for rotor position estimation as described in this paper. Instead, the number of rotor bars, stator slots, and poles were selected for other reasons and by coincidence created an ideal saliency. This saliency is due to the rotor and stator slots producing an air-gap permanence variation that interacts with the fundamental of the stator winding distribution $(P=4, R=28$, and $S=24)$

$$
P=R-S=28-24=4 .
$$

One aspect of the machine design that enhanced the magnitude of the saliency created by the rotor and stator slots was the fact that it was unskewed. Again, the decision not to skew the rotor was chosen for other reasons than to create a saliency, but the fact that it was not skewed did create a larger variation in the inductance than would be present if the rotor was skewed.

The stator transient inductance for this machine can be modeled using (12) with $h=14$

$$
\begin{aligned}
& L_{\sigma s}= \\
& {\left[\begin{array}{cc}
\Sigma L_{\sigma s}+\Delta L_{\sigma s} \cos \left(14 \theta_{r}\right) & -\Delta L_{\sigma s} \sin \left(14 \theta_{r}\right) \\
-\Delta L_{\sigma s} \sin \left(14 \theta_{r}\right) & \Sigma L_{\sigma s}-\Delta L_{\sigma s} \cos \left(14 \theta_{r}\right)
\end{array}\right] .}
\end{aligned}
$$

The rotor position estimate was obtained by exciting the machine with a balanced, three-phase carrier-signal voltage vector. The magnitude of the carrier-signal voltage vector was set equal to $1 \mathrm{~V}(7.1 \%$ of the dc-bus voltage) with a carrier frequency of $1 \mathrm{kHz}$. This resulted in carrier-signal currents that could be modeled using

$$
i_{q d s_{-} c}^{s}=-j I_{c p} e^{j \omega_{c} t}+j I_{c n} e^{j\left(14 \theta_{r}-\omega_{c} t\right)}
$$

where $I_{c p}=2.4 \mathrm{~A}\left(2 \%\right.$ of rated current) and $I_{c n}=0.3 \mathrm{~A}$ ( $0.25 \%$ of rated current).

The estimated rotor position was used to implement an indirect field-oriented torque controller on the test machine. The particular application for this machine required it to only operate as a torque drive, therefore, no speed or position loops were closed on it. For all of the experimental results presented in this paper, the test machine was commanded to provide a desired torque level while the dynamometer, under speed control, went through the desired speed trajectory. Fig. 6 shows an overlay of the estimated and measured rotor positions while the test motor produced a constant torque of $1.5 \mathrm{~N} \cdot \mathrm{m}(31 \%$ of rated) and the dynamometer went through a speed trajectory from 0 to -5 $\mathrm{r} / \mathrm{min}$ to 5 back to $0 \mathrm{r} / \mathrm{min}$. It should be noted that the pronounced quantization present in the estimation error plot was caused by the 8-b oscilloscope used to capture the measured and estimated rotor position signals and does not represent quantization that is actually present in the real signals.

Fig. 7 shows an overlay of the estimated and measured rotor position for the same conditions as Fig. 6 except that the dy- 


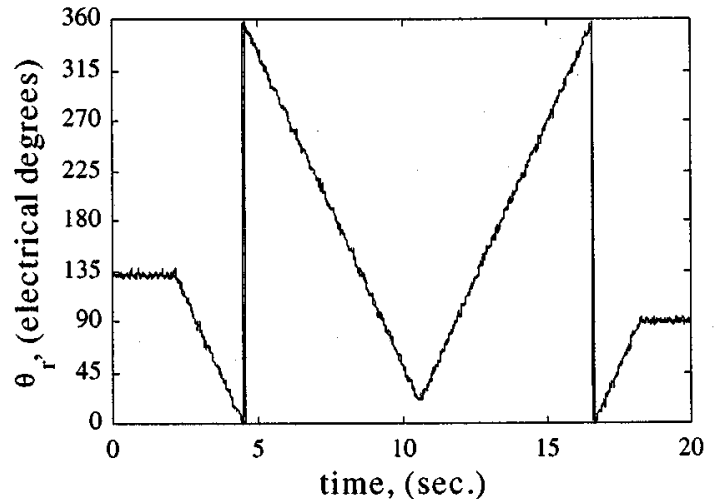

(a)

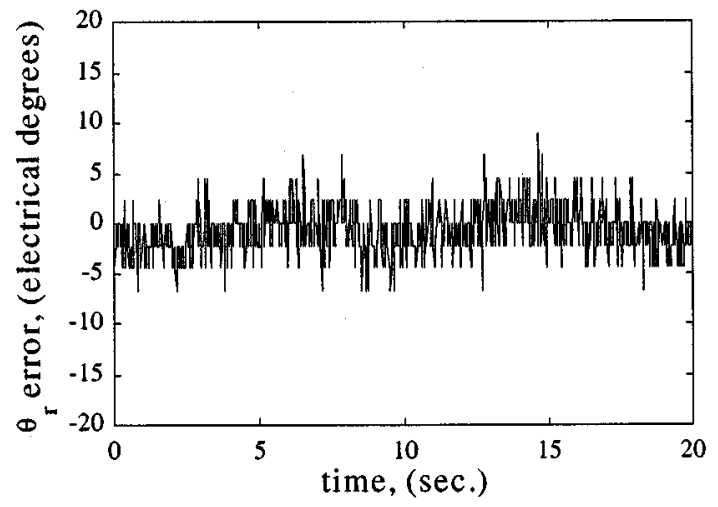

(b)

Fig. 6. Estimated and measured rotor position for steps in the rotor speed ( 0 to $-5 \mathrm{r} / \mathrm{min}$ to 5 to $0 \mathrm{r} / \mathrm{min}$ ). (a) Overlay of measured and estimated rotor position. (b) Error between measured and estimated rotor position.

namometer speed trajectory was changed to 0 to $-50 \mathrm{r} / \mathrm{min}$ to 50 back $0 \mathrm{r} / \mathrm{min}$.

Figs. 6 and 7 show that the estimation technique is capable of sustained operation at low and zero speed. The estimated rotor position tracks the measured rotor position very accurately through speed transients and at zero speed. Experimental results for higher speeds were not included since the rotor position estimate does not degrade as the speed increases and the low-speed operation was felt to be of the most importance.

\section{CONCLUSIONS}

The estimation of rotor position or flux angle independent of operating point, including low and zero speeds (stator frequencies), requires that the estimation technique not be dependent on the rotor speed or fundamental excitation. This results in two conclusions: 1) a trackable spatial saliency must be present in the machine and 2) persistent excitation must be present in the machine in addition to the fundamental excitation, e.g., carrier-signal excitation.

The use of a balanced three-phase carrier-signal voltage excitation to provide this persistent excitation induces both positive- and negative-sequence carrier signal currents in a machine with saliencies. All of the spatial information is contained in the negative-sequence carrier-signal current. The positive-sequence component contains no spatial information and can be filtered off using a synchronous reference frame high-pass filter.

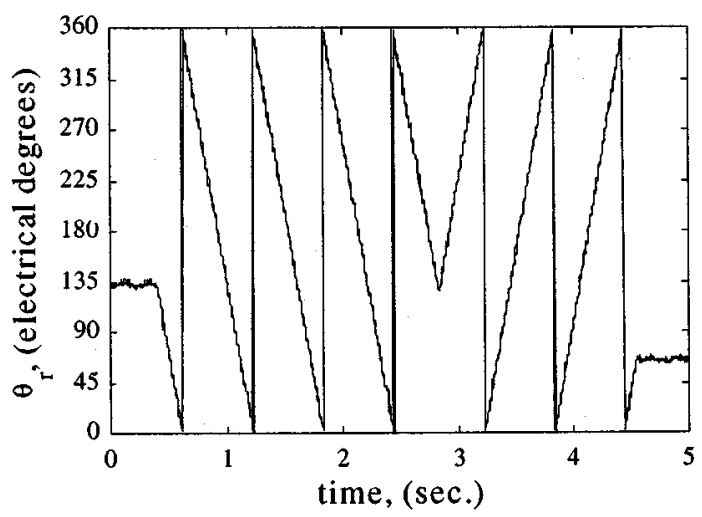

(a)

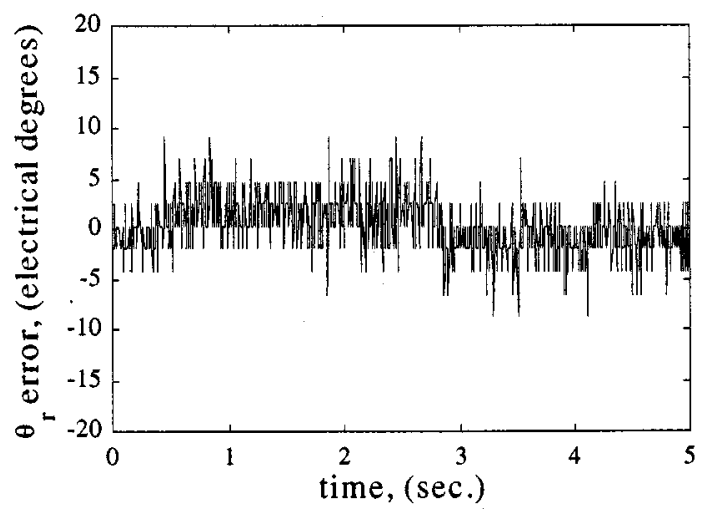

(b)

Fig. 7. Estimated and measured rotor position for steps in the rotor speed $(0$ to $-50 \mathrm{r} / \mathrm{min}$ to 50 to $0 \mathrm{r} / \mathrm{min}$ ). (a) Overlay of measured and estimated rotor position. (b) Error between measured and estimated rotor position.

A tracking observer provides a simple and robust way of extracting the spatial information present in the negative-sequence carrier-signal current. The model of the saliency used in the tracking observer only needs to accurately model the phase, not the magnitude, of the saliency present in the machine. This makes the estimation independent of any machine parameters, which may vary.

Using the saliency created by stator and rotor slotting in some induction machine designs for the estimation of rotor position has several key advantages/benefits.

- In many induction machine designs, it is already present and does not require any further modification to the machine design.

- Creating this type of saliency does not increase the complexity of the machine construction since standard stator and rotor laminations are used, with no special alignment of the laminations necessary, unlike other proposed methods for creating a saliency in induction machines [14], [15], [18]-[20].

- Since it is a harmonic saliency, the effective resolution of the rotor position estimate is increased.

In addition to the saliencies caused by stator and rotor slotting, induction machine designs intrinsically result in many parasitic spatial saliencies. Some of these parasitic saliencies may be large enough to be used for rotor position estimation without modification to the machine design. 


\section{REFERENCES}

[1] C. Schauder, "Adaptive speed identification for vector control of induction motors without rotational transducers," in Conf. Rec. IEEE-IAS Annu. Meeting, San Diego, CA, Oct. 1989, pp. 493-499.

[2] H. Tajima and Y. Hori, "Speed sensorless field-orientation control of the induction machine," IEEE Trans. Ind. Applicat., vol. 29, pp. 175-180, Jan./Feb. 1993.

[3] P. L. Jansen and R. D. Lorenz, "A physically insightful approach to the design and accuracy assessment of flux observers for field oriented induction machine drives," IEEE Trans. Ind. Applicat., vol. 30, pp. 101-110, Jan./Feb. 1994

[4] P. L. Jansen and R. D. Lorenz, "Accuracy limitations of velocity and flux estimation in direct field oriented induction machines," in Proc. EPE Conf., Brighton, U.K., Sept. 1993, pp. 312-318.

[5] M. Ishida and K. Iwata, "A new slip frequency detector of an induction motor utilizing rotor slot harmonics," in Proc. Int. Semiconductor Power Conversion Conf., 1982, pp. 408-415.

[6] _ - "Steady-state characteristics of a torque and speed control system of an induction motor utilizing rotor slot harmonics for slip frequency sensing," IEEE Trans. Power Electron., vol. PE-2, pp. 257-263, July 1987.

[7] D. S. Zinger, T. A. Lipo, and D. W. Novotny, "Using induction motor stator windings to extract speed information," in Conf. Rec. IEEE-IAS Annu. Meeting, San Diego, CA, Oct. 1989, pp. 213-218.

[8] J. Jiang and J. Holtz, "High dynamic speed sensorless AC drive with on line model parameter tuning for steady-state accuracy," IEEE Trans. Ind. Electron., vol. 44, pp. 240-246, Apr. 1997.

[9] J. Holtz, J. Jiang, and H. Pan, "Identification of rotor position and speed of standard induction motors at low speed including zero stator frequency," in Proc. IEEE IECON'97, vol. 2, Nov. 1997, pp. 971-976.

[10] R. M. Cuzner, R. D. Lorenz, and D. W. Novotny, "Application of nonlinear observers for rotor position detection on an induction motor using machine voltages and currents," in Conf. Rec. IEEE-IAS Annu. Meeting, vol. 1, Oct. 1990, pp. 416-421.

[11] A. Ferrah, K. G. Bradley, and G. M. Asher, "Sensorless speed detection of inverter fed induction motors using rotor slot harmonics and fast Fourier transform," in Proc. IEEE PESC'92, 1992, pp. 280-286.

[12] M. Schroedl, "Sensorless control of induction motors at low speed and standstill," in Proc. ICEM, Boston, MA, Aug. 1990, pp. 863-867.

[13] M. Schroedl, D. Hennerbichler, and T. M. Wolbank, "Induction motor drive for electric vehicles without speed- and position sensors," in Proc. EPE Conf., Brighton, U.K., Sept. 1993, pp. 271-275.

[14] P. L. Jansen, "The integration of state estimation, control, and design for induction machines," Ph.D. dissertation, Dep. Elect. Comput. Eng., Univ. Wisconsin, Madison, WI, 1993.

[15] P. L. Jansen and R. D. Lorenz, "Transducerless position and velocity estimation in induction and salient AC machines," IEEE Trans. Ind. Applicat., vol. 31, pp. 240-247, Mar./Apr. 1995.

[16] P. L. Jansen and R. D. Lorenz, "Transducerless field orientation concepts employing saturation-induced saliencies in induction machines," IEEE Trans. Ind. Applicat., vol. 32, pp. 1380-1393, Nov./Dec. 1996.

[17] M. J. Corley and R. D. Lorenz, "Rotor position and velocity estimation for a permanent magnet synchronous machine at standstill and high speeds," in Conf. Rec. IEEE-IAS Annu. Meeting, San Diego, CA, Oct. 5-10, 1996, pp. 36-41.

[18] J. Cilia, G. M. Asher, and K. Bradley, "Sensorless position detection for vector controlled induction motor drives using an asymmetric outersection cage," in Conf. Rec. IEEE-IAS Annu. Meeting, San Diego, CA, Oct. 5-10, 1996, pp. 286-292.
[19] M. W. Degner, "Flux, position, and velocity estimation in AC machines using carrier signal injection," Ph.D. dissertation, Dep. Mech. Eng., Univ. Wisconsin, Madison, WI, 1998.

[20] M. W. Degner and R. D. Lorenz, "Using multiple salliencies for the estimation of flux, position, and velocity in AC machines," IEEE Trans. Ind. Applicat., vol. 34, pp. 1097-1104, Sept./Oct. 1998.

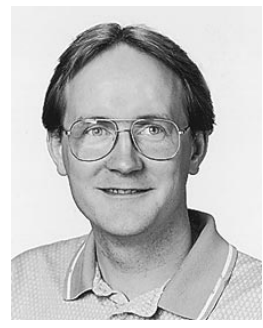

Michael W. Degner (S'95-A'98) received the B.S., M.S., and Ph.D. degrees in mechanical engineering with a focus on electromechanics and control from the University of Wisconsin, Madison, in 1991, 1993, and 1998, respectively.

He is currently with Ford Research Laboratory, Ford Motor Company, Dearborn, MI, where his research is focused on the use of power electronics in automobile applications. His interests include control systems, machine drives, electric machines, power electronics, and electromechanics.

Dr. Degner received the Second Prize Paper Award from the Industrial Drives Committee and the Third Prize Paper Award from the Industrial Power Converter Committee at the 1997 IEEE Industry Applications Society Annual Meeting.

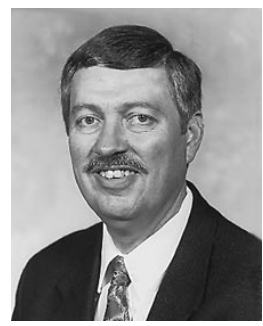

Robert D. Lorenz (S'83-M'84-SM'91-F'98) received the B.S., M.S., and Ph.D. degrees from the University of Wisconsin, Madison, in 1969, 1970, and 1984, respectively.

Since 1984, he has been a Member of the Faculty of the University of Wisconsin, Madison, where he is the Consolidated Papers Foundation Professor of Controls Engineering in both the Mechanical Engineering and Electrical and Computer Engineering Departments. In this position, he acts as Co-Director of the Wisconsin Electric Machines and Power Electronics Consortium. He is also an active consultant to many organizations. He was a Visiting Research Professor in the Electrical Drives Group, Catholic University of Leuven, Leuven, Belgium, in the summer of 1989 and in the Power Electronics and Electrical Drives Institute, Technical University of Aachen, Aachen, Germany, in the summers of 1987, 1991, 1995, 1997, and 1999. From 1969 to 1970 , he did his thesis research for the M.S. degree at the Technical University of Aachen. From 1972 to 1982, he was a Member of the Research Staff at the Gleason Works, Rochester, NY. His current research interests include sensorless electromagnetic motor/actuator technologies, real-time signal processing and estimation techniques, precision multiaxis motion control, and ac drive and high-precision machine control technologies.

Dr. Lorenz is currently the IEEE Industry Applications Society (IAS) Vice President/President Elect, a Distinguished Lecturer of the IAS for 2000/2001, the immediate past Chair of the IAS Awards Department, past Chairman of the IAS Industrial Drives Committee, and a member of the IAS Industrial Drives, Electric Machines, Industrial Power Converter, and Industrial Automation and Control Committees. He is a member of the IEEE Sensor Council AdCom and the IEEE Neural Network AdCom. He is a Registered Professional Engineer in the States of New York and Wisconsin. He is also a Member of the American Society of Mechanical Engineers, Instrument Society of America, and Society of Photo-Optical Instrumentation Engineers. 